\title{
A RETÓRICA TROVADORESCA DE DOM DINIS, O REI QUE NÃO TIRA A COROA AO TROVAR ${ }^{1}$
}

\section{The troubadours' rhetoric of Dom Dinis, the king who did not take out the crown to composse troves}

\author{
Ana Luiza Mendes \\ Doutora em História pela Universidade Federal do Paraná (UFPR) \\ E-mail: analuizam982@gmail.com \\ ORCID: https://orcid.org/0000-0002-2291-1417
}

Recebido em: 30/10/2019

Aprovado em: 20/03/2020

\begin{abstract}
Resumo : O presente artigo tem o objetivo de analisar a produção trovadoresca de Dom Dinis no tocante à retórica poética utilizada para a afirmação de uma identidade artística. Dom Dinis foi o maior trovador português, cuja memória ainda é retomada na atualidade para definir os contornos da cultura e identidade portuguesa. As composições dionisinas, por vezes fazendo referências aos provençais, iniciadores do movimento trovadoresco, mostra seu conhecimento da tradição, demonstrando sua educação culta e erudita que contribuiu para que estivesse em sintonia com o conhecimento da cultura em voga na sua época. Alguns estudiosos veem as menções aos provençais como uma homenagem ou, ainda, cópia. Contudo, é possível verificar que o rei-trovador utiliza esses mecanismos como base retórica para defender sua produção frente à provençal.
\end{abstract}

Palavras-chaves: Dom Dinis, retórica poética, trovadorismo

Abstract : This article aims to analyze Dom Dinis' troubadourism production, regarding the poetic rhetoric used for the affirmation of an artistic identity. Dom Dinis was the greatest Portuguese troubadour whose memory is still taken up today to define the contours of Portuguese culture and identity. Dionysian compositions, sometimes making references to Provencals, initiators of the troubadourism movement, it shows its knowledge of tradition, demonstrating their cultured and erudite education that contributed to being in tune with the cultural knowledge in vogue in their time. Some researchers see the mention of Provencals as a tribute or even a copy. However, it is possible to verify that the king-troubadour uses these mechanisms as rhetorical basis to defend his production against the Provencal one.

Key-words: Dom Dinis, poetic rhetoric, troubadorism 
O estudo da literatura medieval é um tema relativamente novo na historiografia. É fruto da revolução historiográfica promovida por historiadores reunidos no que comumente se chama de "Escola dos Annales", desenvolvida nos anos de $1920 \mathrm{em}$ diante, cujo intuito era ultrapassar a História puramente política. Nesse contexto, as possibilidades de metodologias e fontes históricas foram ampliadas contribuindo para uma abrangência maior da visão que o historiador pode ter de uma sociedade. No contexto brasileiro, a influência dessa abordagem historiográfica se deu a partir dos anos de 1980, com o final da ditadura militar e a abertura política.

Porém, isso não se deu sem ressalvas e críticas, uma vez que a concepção, influenciada pelo marxismo, era de que a História deveria ser engajada e visar à ruptura. Dessa forma, além de não se atentar à literatura como fonte primária, a Idade Média também não estava no escopo dos estudos historiográficos brasileiros, pois eles passaram a compreender o conceito de longa duração, de Fernand Braudel, que, entre outros elementos, aponta para as permanências.

Por outro lado, a difusão dos "autores midiáticos franceses" (COELHO, 2006, p. 30) contribuiu para desmistificar a objetividade do texto, uma vez que se considerava que ele, sobretudo o que provinha da oficialidade, era desprovido de subjetividade o que contribuiria para um conhecimento objetivo e verdadeiro do passado. A partir dessa nova perspectiva de análise hoje se tem consciência de que a total objetividade não existe, assim como o alcance da verdade. Também se tem consciência de que o texto, ainda que oficial, não é neutro, uma vez que transmite ideias que podem legitimar determinadas estruturas sociais. Essa é a linha condutora do pensamento historiográfico de Georges Duby que defende que a sociedade medieval deve ser analisada sob todos os seus aspectos, visto o fato das esferas sociais estarem conectadas entre si.

Nessa perspectiva insere-se o estudo das cantigas trovadorescas que podem revelar muito mais do que os componentes poéticos e idealizados da literatura, uma vez que não se pode dissociar a sua produção do seu aporte concreto, da realidade da qual ela foi testemunha.

A abordagem historiográfica da poesia pretende, portanto, explorá-la a fim de compreender como a realidade é pensada, interpretada e transmitida por meio da linguagem e de elementos poéticos. Para Nicolau Sevcenko, a Literatura fala ao historiador sobre a História que não ocorreu, sobre possibilidades que não vingaram, sobre planos que não se concretizaram. "Ela é o testemunho triste, porém sublime, dos homens que foram vencidos pelos fatos" (SEVCENKO, 2003, p. 30).

Dessa forma, compreende-se que as cantigas trovadorescas são fontes ricas que possibilitam visualizar diferentes facetas da Idade Média. Contudo, é necessário ter em mente a carga subjetiva e ficcional que as engendram. Como aponta Roger Chartier, o historiador não deve sucumbir e tratar essas fontes como espelhos, reflexos não 
problemáticos de um tempo (BURKE, 2005, p. 32-33). As cantigas, portanto, também devem ser interpretadas como discursos que possibilitam a identificação de como uma determinada realidade e conceitos são construídos e transmitidos. Tal abordagem contribui para o enriquecimento da produção historiográfica, uma vez que insere em sua discussão elementos culturais pertinentes à compreensão do homem e do mundo medieval que por muito tempo ficou relegado ao anonimato. Tal abordagem das fontes trovadorescas contribui para entender como os medievais compreendiam a si mesmos, como expressavam suas emoções e como compreendiam o seu mundo:

\footnotetext{
Neste diversificado e complexo universo, a literatura acabou fixando-se como uma fonte altamente produtiva, pois permitiu aos pesquisadores da cultura em geral - e aos historiadores - em especial - adentrarem em um universo amplo e repleto de significações/representações, pois como a incorporação deste tipo de artefato na produção historiográfica, passamos a considerar "novas maneiras de pensar a história" e questionar antigos padrões e verdades históricas pré-estabelecidas (SENA JUNIOR, 2010, p. 4).
}

Além disso, as fontes literárias podem ser compreendidas como um relato do contexto sociocultural na qual estão inseridas, contribuindo para pensar a realidade medieval por uma diferente perspectiva, relacionada à subjetividade que se constitui em importante elemento para a percepção da realidade e para a construção de significados e discursos sobre ela. As cantigas galego-portuguesas se enquadram, portanto, nesse conceito, permitindo um diálogo entre ficção e realidade, dando-nos a possibilidade de mostrar os percursos da construção de uma identidade cultural.

Para realizar a análise dessas fontes, a pesquisa se desenvolveu numa perspectiva de interdisciplinaridade entre a História e os Estudos Literários que, justamente, são as áreas que concentram o maior número de estudos sobre a Literatura Medieval no Brasil, constatação feita por Márcio Muniz, num artigo no qual apresenta um mapeamento e um debate avaliativo da produção bibliográfica, com base nas publicações da ABREM (Associação Brasileira de Estudos Medievais), acerca da literatura medieval (MUNIZ, 2009).

O diálogo entre as duas áreas se faz profícua por conta da particularidade das fontes examinadas que revelam elementos de escopo literário e histórico que são complementares. Tal perspectiva, no entanto, pode ser considerada como recente no âmbito historiográfico. Como aponta Maria Filomena Coelho, somente a partir da década de 1980 as temáticas sobre a Idade Média se revitalizaram no Brasil graças, sobretudo, à difusão dos medievalistas franceses que, décadas antes, se comprometeram a modificar a concepção de História, ampliando seus horizontes e fontes de estudo (COELHO, 2005). Assim, esse trabalho insere-se na tradição dessa mudança de perspectiva historiográfica e da reforma de hábitos de trabalho, nas maneiras de pensar e sentir (ZUMTHOR, 2009), o que possibilitou que os estudiosos voltassem o seu olhar para a literatura medieval.

Todavia, é necessário ter em mente que essa literatura não é uma literatura como a compreendemos atualmente. Ela reflete uma característica do período: a oralidade. "A obra medieval, até o século XVI, só tem existência plena quando sustentada pela voz" (MEDEIROS, 2008, p. 105). Dessa forma, o termo literatura para a expressão cultural 
do período medieval pode conter uma conotação ambígua, uma vez que o seu conceito pressupõe a atividade da escrita. Como afirma Michel Zink,

\begin{abstract}
Até meados do século XII, as jovens literaturas vernáculas conheciam apenas os gêneros cantados: a canção de gesta, a poesia lírica. A primeira conserva artificialmente as marcas da oralidade, mesmo quando é escrita (sem o quê, o que saberíamos dela?): encenação do recitante, interpelação do público, efeitos de eco e repetições ligados à composição estrófica. A segunda, que exige do poeta que seja também compositor, às vezes denuncia seu modo oral de transmissão, ao nomear o menestrel a cuja memória se confiou a canção ou a desejar que ela encontre um cantor digno de si. O romance é o primeiro gênero (se, no início, esta forma nebulosa merece esse nome) destinado à leitura, mas é uma leitura em voz alta. A arte dos menestréis deixa amplo espaço à mímica e à interpretação dramatizada: ver-se-ão, mais tarde, suas consequências, tanto para o desenvolvimento do teatro quanto para a definição do eu poético. A voz, com sua qualidade e timbre próprios, faz parte integrante da arte literária. Entre os trovadores, os dons de intérprete e de músico são frequentemente confundidos (ZINK, 2002, p. 81).
\end{abstract}

O autor se refere à literatura do século XII, mas ainda em séculos posteriores ela guardará as características da oralidade. Além disso, essa literatura é extremamente performática e tinha o objetivo de entreter a corte na qual ela foi criada ou cantada e educá-la sobre os costumes daquele meio social. A literatura medieval se constitui, portanto, como uma retórica dos sentidos, cujo significado é fundamentado num discurso que fornece indícios sobre o real, mas nunca o real completo como supõe Segismundo Spina quando afirma que as cantigas de amigo e de amor galegoportuguesas são um retrato fiel da vida sentimental portuguesa.

A relação entre a fidelidade e a realidade aparece, inclusive, como mote de uma cantiga de Dom Dinis em que ele joga com a concepção da realidade do sentimento amoroso difundido por ele e pelos trovadores provençais. Há que prestar atenção na retórica. As cantigas serviam também ao propósito de divulgação de uma imagem. E essa imagem estava sendo veiculada por um trovador que também era rei. É possível pensar, pois, num intercâmbio de retóricas, uma cultural e outra política, por meio do qual o rei-trovador empreendia sua legitimidade em diferentes vertentes.

Nesse sentido, pode-se dizer que as cantigas não são "somente" literatura. Há que se ter em mente que as fontes históricas não são de todo objetivas, uma vez que "o pano de fundo não é neutro" (DUBY,1993, p. 40), de modo que ao se debruçar sobre elas também estudamos sobre as suas intenções, que transitam em diferentes áreas, incluindo o da tênue relação entre real e ficção que elas transmitem. Ou ainda, a relação entre real e ideal que é, por si só, uma possibilidade de investigação acerca de elementos presentes nas composições, pode suscitar diferentes perspectivas sobre as produções dionisinas que não devem ser dissociadas do seu aporte concreto do qual emergiam e para o qual convergiam propósitos diversos, mas complementares.

As cantigas do rei-trovador são compreendidas não só como fruto de um movimento cultural que ganhou diferentes cores com o trovador Dinis, mas também como método utilizado por ele para legitimar seu poder e sua autoridade perante a nobreza que procurou combater em diferentes frentes e manter sob controle. 
O período efervescente do trovadorismo em Portugal coincide com o reinado de Afonso III (1248-1279), em cujo ambiente de cultura cortês se desenvolverá a formação de Dom Dinis que irá relembrar, ou ainda, afirmar, em uma composição que tem ciência dessa tradição. Em Proençaes soen mui bem trovar, Dinis legitima sua prática trovadoresca remetendo aos seus fundadores, mas se coloca além dela, demonstrando originalidade e consciência da sua ação poética que se insere na compreensão do sentido que a prática trovadoresca tinha para os seus atores.

\author{
Proençaes soem mui bem trobar \\ e dizem eles que é com amor; \\ mais os que trobam no tempo da flor \\ e nom em outro, sei eu bem que nom \\ ham tam gram coita no seu coraçom \\ qual m'eu por mia senhor vejo levar. \\ Pero que trobam e sabem loar \\ sas senhores o mais e o melhor \\ que eles podem, sõo sabedor \\ que os que trobam quand'a frol sazom \\ há e nom ante, se Deus mi perdom, \\ nom ham tal coita qual eu hei sem par. \\ $\mathrm{Ca}$ os que trobam e que s'alegrar \\ vam eno tempo que tem a color \\ a frol consig'e, tanto que se for \\ aquel tempo, log'em trobar razom \\ nom ham, nem vivem [em] qual perdiçom \\ hoj'eu vivo, que pois m'há de matar.
}

(LOPES; FERREIRA, 2011)

Nessa cantiga, Dom Dinis satiriza o trovar dos provençais "e assume-se como representante e defensor de uma tradição lírica que, não obstante a sua matriz extrapeninsular, não deixa de se afirmar pelo seu valor próprio" (MANSO, 2013, p. 972).

A ironia pode ser identificada no segundo verso, quando somos introduzidos ao dizem eles que é com amor, cuja ideia não é corroborada pelo eu-lírico. Para ele, os provençais dizem amar, mas não amam de fato, pois esse sentimento só é demonstrado no tempo da frol, ou seja, da primavera, uma das características mais habituais das composições trovadorescas, como podemos observar a seguir, nas obras de Guilherme da Aquitânia e de Jaufre Rudel (1125-1148), respectivamente:

Com a doçura do tempo novo

florescem os bosques e as aves cantam cada uma delas no seu latim segundo os versos do novo canto; convém portanto que se ocupe assim cada um daquilo que mais anseia.

(LOPES, 2006) 
vou, de desejo, curvado e triste

tal que nem cantos nem flores de branco-

[espinho

me agradam mais que o inverno gelado.

(LOPES, 2006)

Dom Dinis, dessa forma, ironiza e critica um clichê temático dos trovadores provençais, denunciando a artificialidade desse sentimento, diferentemente do seu próprio, expresso pelo trovadorismo peninsular. Dessa maneira, como afirma Segismundo Spina, as composições galego-portuguesas podem ser compreendidas como poesias intelectuais, no sentido em que expressam consciência do fazer poético e, no caso do rei português, da consciência do uso de uma forma canônica de trovar para empreender uma sátira a ela mesma ou, ainda, concretizar "um ideal de condensação, de recapitulação e síntese de toda a tradição poética e, ao mesmo tempo, de confronto criativo" (LOPES, 2006).

Ao se referir aos provençais Dom Dinis afirma a singularidade da sua produção cultural frente à tradição trovadoresca. Ela é retomada de forma a reconhecê-la, mas também com o intuito de demonstrar a possibilidade de se diferenciar dela, como podemos verificar a partir de cantigas em que o rei-trovador demonstra sua consciência poética ao se inserir na tradição:

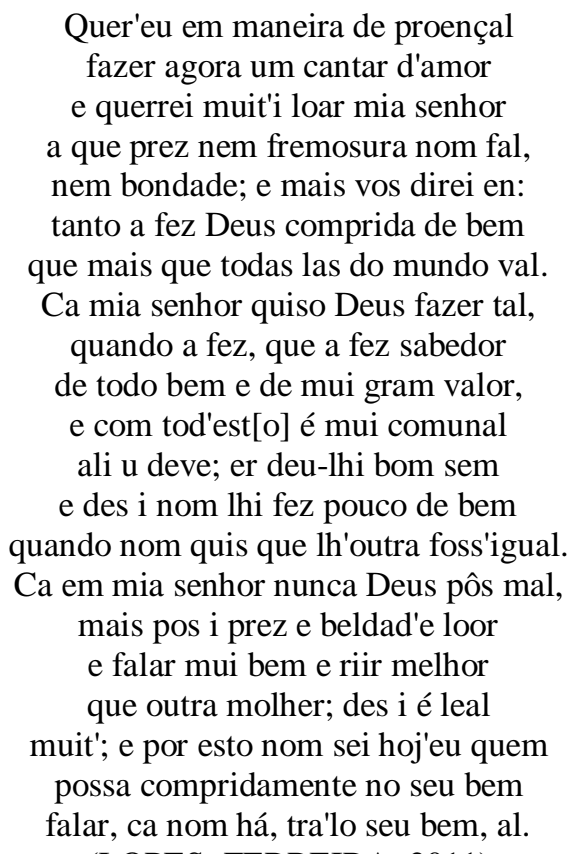

(LOPES; FERREIRA, 2011)

Nessa composição, Dom Dinis afirma trovar como os provençais. De fato, nela está presente um dos principais elementos do amor cortês provençal: o elogio à dama. A cantiga serve para que o trovador celebre o seu amor pela sua dama que não se compara a nenhuma outra mulher no mundo. Dom Dinis faz um louvor superlativo à sua senhor que é sociável, repleta de bondade e beleza. Como prediz a norma cortês, o nome da dama não é exposto. Expõe-se somente a submissão do trovador que espera que ela retribua seu amor e devoção com um bem, isto é, uma recompensa, que poderia ser um presente, um olhar ou algo mais significativamente físico. 
Segundo Mónica Andrea de Sousa Neves, "ao fazer referência ao trovar ao modo provençal o sujeito poético parece querer dar a entender que não tem eloquência suficiente para louvar uma tal dama e para isso recorre ao estilo exuberante dos poetas occitânicos" (2004, p. 80). Entretanto, essa perspectiva seria uma forma de simplificar a composição dionisina que engloba questões mais abrangentes e complexas que a pura repetição de uma fórmula convencional de trovar sobre o sentimento amoroso. Nessa cantiga pode-se perceber a consciência artística desenvolvida pela referência metapoética existente na informação de que fará um cantar d'amor. Isso revela conhecimento das regras poéticas que delimitam esse gênero, como também pressupõe a consciência do fazer trovadoresco, uma vez que fala sobre a própria composição e sobre o seu processo de criação.

Trovando em maneira de proençal, ele "não só confirma o seu o perfeito conhecimento da lírica provençal, mas também a consciência que tinha de ser 'a maneira provençal' a matriz do género galego-português a que pertence esta composição, a cantiga de amor" (LOPES; FERREIRA, 2011). Contudo, mais do que ter consciência de que a cantiga de amor deveria seguir essa fórmula, Dom Dinis demonstra e aplica seu conhecimento da tradição e técnica provençais, corroborando a ideia da efervescente troca cultural exercida no período medieval na qual ele estava inserido e da qual utiliza para atualizá-la. Assim, ainda que empregando a técnica e o tema do amor cortês proveniente do trovadorismo provençal, é possível verificar que a produção do rei português ganhou diferentes contornos que o incluem dentro da tradição especificamente galego-portuguesa que ele também atualiza, pois insere elementos originais e, em certos casos, únicos.

Para além da ironia, a cantiga se destina ao louvor da senhor, nos moldes do amor cortês. A ela se destinam todos os elogios que o vassalo amoroso tem o dever de enunciar para, assim, defini-la como incomparável a nenhuma outra no mundo. O tópico do elogio à senhor é um tema recorrente na produção dionisina, ao qual juntam-se outros elementos que comungam com o imaginário do amor cortês, como a vassalagem amorosa, pois o amor cantado pelos trovadores é inseparável do desejo, do serviço e da cortesia (LOPES, 2006, p. 8). Como produções de um trovador consciente do seu mester, as cantigas de Dom Dinis emanam desejo que nem sempre paira sobre a aura da contenção pregada pela cortesia.

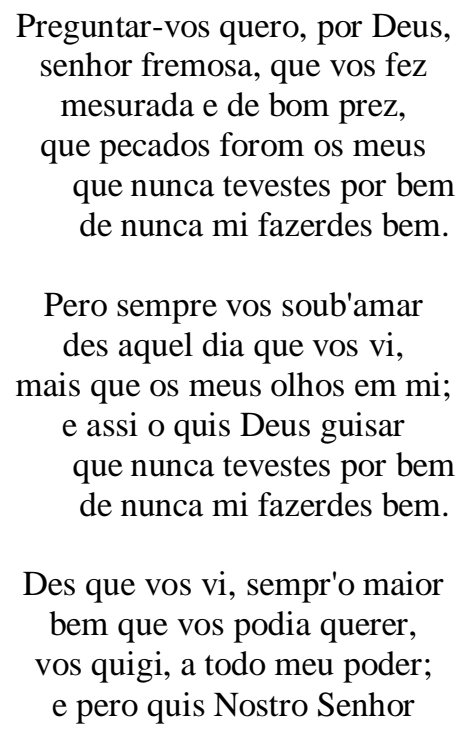


que nunca tevestes por bem de nunca mi fazerdes bem.

Mais, senhor, a vida com bem se cobraria: bem por bem.

(LOPES; FERREIRA, 2011)

Nessa cantiga há os devidos elogios à senhor que é fremosa, mesurada e de bom prez, ou seja, formosa, cortês e de mérito, revelados na forma de tratar o trovador que reclama o fato de ela nunca ter feito um bem para ele. Como manda a sociabilidade cortês, as paixões devem ser mesuradas e o amor cortês tem o propósito de ensinar essa contenção que, para alguns estudiosos, demonstra um amor que permanece no plano do ideal e, portanto, não realizado. No entanto, a finda ${ }^{2}$ da cantiga, ao explicitar o pedido de pagamento de bem com bem, sugere a possibilidade desse amor ultrapassar o aspecto platônico, uma vez que a recompensa pela atenção dispensada pelo trovador ia desde uma $d o \tilde{a}^{3}$ à efetivação amorosa.

No trovadorismo provençal também podemos verificar um não tão espiritual amor:

J'ai été en cruelle douleur pour un chevalier que j'ai eu, je veux qu'il soit pour toujours su que je l'aimais par-dessus tout. Je voudrais tant mon chevalier tenir un soir entre mes bras nuet qu'il se trouve comblé,

que je lui serve de coussin.

Je suis plus amoureuse de lui que jamais Floris de Blanchefleur, je lui donne mon coeur, mon amour, mon sens, mes yeux et ma vie.

Bel ami élégant et bon, quand vous tiendrai-je en mon pouvoir ? Quand coucherai-je avec vous un soir, vous donnant un baiser amoureux ?

Sachez que j'ai grand désir de vous à la place du mari, pourvu que vous m'ayez promis de faire tout ce que je voudrais.

(Bibliotèque Nationale de France)

Tenho sofrido uma aflição por cavaleiro que passou; quero que saiba como estou atribulada de paixão; hoje sei que fui traída por não ter dado o meu amor, pois é meu erro e meu pudor estar na cama vestida.

Queria ter ao rés do chão o cavaleiro ainda nu, ou que ele achasse mais azul 


$$
\begin{gathered}
\text { se transformar em meu colchão; } \\
\text { estou mais enlouquecida } \\
\text { do que Floris por Brancaflor: } \\
\text { eu dei meu peito e meu amor, } \\
\text { dei meu senso, olhar e vida. } \\
\text { Meu belo amigo encantador, } \\
\text { quando você será só meu? } \\
\text { Deitados na noite, no breu, } \\
\text { pra dar os beijos deste amor! } \\
\text { Você sabe: eu amaria } \\
\text { trocar meu homem por você, } \\
\text { e só precisa prometer } \\
\text { fazer tudo que eu queria. }
\end{gathered}
$$

Essa é uma cantiga de Beatriz, Condessa de Dia (1140-1212), um dos poucos nomes de trobairitz que chegaram até nós. Nela, a compositora manifesta que não ama seu marido, mas um cavaleiro que um dia conheceu. $\mathrm{O}$ amor que ela descreve está muito distante da contensão prevista pelo amor cortês. Há aqui a referência explícita ao amor carnal que é apenas uma possibilidade de interpretação na cantiga de Dom Dinis. Outra comparação que pode ser feita a partir dessas duas composições é o fato de que na cantiga provençal há a explicitação de outro importante elemento constituinte do amor cortês: a incompatibilidade entre amor e matrimônio. A dama está comprometida com o marido por meio do contrato de casamento, porém é ao cavaleiro que seu amor se destina, consoante, portanto, com a concepção de que na conjugalidade não havia espaço para a cupiditas, o amor carnal, mundano, de forma que entre esposos, só poderia haver a caritas, o amor espiritual.

Diferentemente da lírica provençal em que o trovador cantava seu amor, geralmente, a uma dama casada, no trovadorismo português o foco da atenção amorosa é para a donzela, de modo que o tema da dicotomia entre casamento e amor livre pode não ser visualizado na lírica ibérica. As composições dionisinas permitem, portanto, visualizar outra concepção de amor cortês suscitada pelo rei-trovador, como sugere a seguinte cantiga:

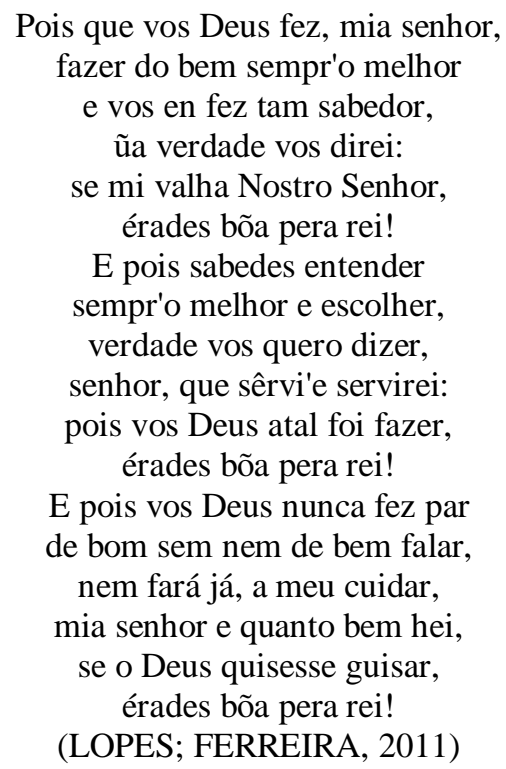


Alguns estudiosos, como Ana Rodrigues de Oliveira, defendem a ideia de que essa cantiga seria destinada à rainha Isabel (1270-1336) que, de fato, era boa para rei. Criada na corte de Aragão, a rainha tinha dotes que a tornavam um excelente partido a ser requisitado por herdeiros de Inglaterra, Nápoles, Sicília e para o já, então, rei de Portugal.

Casando com a herdeira de Pedro III de Aragão (1239-1285), Dinis efetivava uma aliança na Península que daria aos dois reinos respaldos num possível conflito com Castela, o mais poderoso reino da Península que tinha pretensões expansionistas perante as quais Portugal deveria se salvaguardar.

Da mesma forma, Pedro III também via o casamento de sua filha com o rei português como vantajoso, uma vez que Aragão estava envolvido em conflitos com a França e com o Papado, de modo que a definição de uma aliança politicamente forte poderia auxiliar no desfecho desses entraves. Por sua vez, a união com Isabel dava a Dom Dinis um aliado nas lutas que travava com seu irmão, representante dos descontentamentos nobiliárquicos perante o rei. O casamento, "inseria-se, assim, num conjunto de estratégias familiares, dinásticas e políticas pela hegemonia ibérica nos finais do século XII e início do XIV, revelando, também, uma disputa a nível internacional envolvendo o reino francês, o conde de Anjou e o papado" (OLIVEIRA, 2010, p. 160).

Sobre a infância de Isabel em Aragão praticamente nada se sabe. As fontes só nos dão informações que revelam a sua prematura vocação para a santidade. Grande parte dos documentos provém de obras hagiográficas que contribuem para mesclar mito e realidade. De fato, sua educação prezava pela reverência religiosa, mas não se restringia a esse aspecto. Pedro de Aragão foi educado pela espada e pela pena. Por conta da influência catalã tinha conhecimentos políticos-militares e trovadorescos (NEMÉSIO, 2011, p. 15-16). Ou seja, Isabel foi educada numa corte culta e, sendo ela filha de rei, importante moeda de troca, também deveria seguir os passos de uma culta educação então prezada no contexto ibérico que forjava um novo conceito de mundo, de experiências e de sociabilidades.

Isabel mostrou-se extremamente consciente do conturbado contexto político ibérico. Pelas correspondências por ela escritas podemos supor que ela também tinha uma aguçada consciência política que aplicava por meio da diplomacia para a solução de conflitos externos e internos. No que diz respeito ao reino português, a rainha se posicionou firmemente contra a legitimação dos filhos do infante Dom Afonso, irmão do rei, revelando sua intenção de proteger os direitos dos seus filhos e do reino.

Mais tarde ela também se posicionou contra uma das sobrinhas que reivindicava a herança de Dom Afonso. Apesar de Dom Dinis ter tomado uma decisão diferente do que defendia sua esposa, as fontes, sobretudo as correspondências, possibilitam identificar uma rainha que prezava pela participação na vida política do reino, deixando bem claro suas opiniões bem fundamentadas. Outro episódio em que é possível identificar sua atuação foi o conflito protagonizado pelo rei português e o herdeiro do trono. A princípio, a rainha procurou apaziguar o embate por meio da diplomacia. Escreveu para que o papa João XXII (1244-1334) advogasse pela causa e ajudasse a solucionar a situação. A resposta do Papa foi em forma de uma bula, datada de 31 de outubro de 1320, em que declarava suas preocupações acerca do conflito, assim como atestava que nunca houve da parte de Dom Dinis o pedido para legitimar o bastado Afonso Sanches 
(1289-1329) para que ele assumisse o trono após a sua morte, como o infante herdeiro alegava ter ocorrido.

Isabel atuou para conciliar diferentes interesses e exerceu distintos papéis na mediação desse conflito: mãe, esposa e rainha. Exigiu que o rei fosse justo e que o infante fosse obediente ao seu rei. Ao exigir que ele fosse a Leiria para se entender com Dom Dinis, teve restituídos seus direitos, funções e bens que ela administrava com apurado tino. As correspondências de Isabel revelam, ainda, seu aguçado discernimento sobre a constituição de alianças políticas por intermédio de casamentos. O enlace do Conde Dom Pedro (1287-1350), bastardo de Dom Dinis, com uma dama aragonesa que acompanhou o séquito da rainha quando do seu casamento com o rei português, Maria Ximenez, foi intermediado pela rainha portuguesa diretamente com Jaime II (12671327).

Isabel também tinha uma importante rede de relações e influência política, suposto pelo fato de que ela mesma solicitava que os bastardos de Dom Dinis fossem enviados cedo aos seus cuidados. Isso demonstra a consciência da rainha em torno da importância que os filhos do rei poderiam ter nas relações políticas do reino.

Essas breves considerações contribuem para identificar Isabel como uma rainha ativamente inserida na conjuntura política ibérica e com ampla consciência do papel que the era destinado. Assim, pode-se dizer que ela era, de fato, "uma esposa deliciosa e uma estratégia política ideal" (PINTO, 1982, p. 86) e, pode realmente ser considerada "boa para rei".

Porém, deve-se considerar que muito do que sabemos sobre ela é delineado pelas tramas da construção de um discurso e de uma imagem que se perpetuou por séculos. Evidente que não se pode deixar de lado o aspecto religioso que circundava suas ações, mas elas próprias podem ser compreendidas em sintonia com o contexto político da época.

Desse modo, a afirmação categórica de que a cantiga se destinaria à rainha seria uma forma de legitimar a imagem do seu destino santo e imaculado. Porém, não há nenhuma indicação na composição dionisina de que ela é direcionada à rainha. A ausência do destinatário está de acordo com as regras do amor cortês, as quais decretam que não se referencie o nome da dama para a qual a cantiga se destinaria. Julgar que seria para Isabel seria um movimento coerente com o contexto de sua atuação, mas um tanto simplista, uma vez que se tem conhecimento da relação de Dom Dinis com as mulheres, como pressupõe as referências às suas barregãs, Dona Branca Lourenço de Valadares; Dona Maria Rodrigues de Chacim, neta do seu mordomo mor, Dom Nuno Martins; Dona Aldonça Rodrigues de Telha mãe de Afonso Sanches; Dona Gracia Anes, mãe de Dom Pedro, conde de Barcellos; Dona Maria Pires, mãe de João Afonso, posteriormente morto a mando de Afonso IV; Dona Marinha Gomes, mãe de Maria Afonso I, segundo informações constantes no Livro de Linhagens do Conde Dom Pedro.

Outro aspecto para questionar a afirmação de Isabel como a destinatária da cantiga é o fato de que o amor cortês nela representado pregava que o amor não era encontrado no casamento ao qual era reservado apenas 
como a si mesmo. Em contrapartida, a esposa deveria reverenciá-lo, obedecêlo (MACEDO, 2013, p. 26).

Assim, dedicar a cantiga à esposa seria praticar uma heresia a esse preceito cortês. Além disso, o amor cortês era mundano e carnal, cuja função "é justamente puxar o excesso de calor, de fervor, para fora da célula conjugal a fím de a manter no estado de moderação que lhe fica bem" (DUBY, 1988, p. 154), preceitos bem distantes daqueles praticados pela rainha Isabel. Pelo fato de Isabel ter gerado apenas dois filhos, pode-se supor que ela seguiu estritamente o discurso religioso oficial que condenava o prazer físico e concebia o sexo

apenas por sua função procriativa. Segundo o ponto de vista de moralistas e teólogos, os movimentos realizados entre quatro paredes, no leito, deviam ser disciplinados, qualquer expediente contraceptivo era culposo e, quando a descendência já estivesse assegurada, seria conveniente evitar o contato carnal (MACEDO, 2013, p. 26),

levando o marido a outros meios de exprimir sentimentos e de satisfação sexual, como a busca por prostitutas e os jogos cortesãos (SANTOS-SILVA, 2014, p. 155). Deve-se mensurar a realidade dessa composição, porém "real ou sublimado, as cantigas de amor são registro de uma sociedade que, ao menos em seu discurso, está muito interessada em sedução" (GONÇALVES, 1993, p. 17). E o discurso é tão importante quanto a realidade.

Nesse contexto, a cantiga poderia se referir a qualquer mulher que o rei tenha tido em seus braços. Todavia, não se pode deixar de lado o aspecto ficcional dessas composições. Como salienta Elsa Gonçalves (1993, p. 17), a comparação entre o trovador e governantes é um topos comum tanto na lírica provençal, com Bernart de Ventadorn, Bernart Marti ou Cadenet, quanto na galego-portuguesa, com Joan Soares Coelho e Afonso Pais de Braga ou Pai Soares de Taveirós.

Com esse tema, Dom Dinis insere-se na tradição, mas as cantigas ganham um significado diferente, pois nenhum dos trovadores que utilizaram o tema foram realmente reis ou imperadores. "Por isso podia galantear uma dona dizendo-lhe 'erades boa pera rei' ou então afirmar, com irónica superioridade, que não trocaria a recompensa do amor pela condição de rei ou infante. A cantigas como estas cremos poder chamar "poesia de rei"' (GONÇALVES, 1993, p. 17).

A mulher aparece de forma implícita nessa cantiga, como um recurso poético. Quem está em primeiro plano é o próprio rei que, por intermédio do elogio à senhor, elogia a si mesmo, pois somente uma mulher criada sem par, inigualável a qualquer outra estaria no patamar do rei que exige perfeição. Nessa perspectiva, o rei-trovador usa sua condição régia como argumento de sedução.

A afirmação "érades bõa pera rei”, repetida como refrão nas coblas 


\begin{abstract}
5 seguintes, poderia ser simplesmente interpretada como o culminar do panegírico feito no corpo da cobla, não fora o seu autor ser ele próprio rei. Desta feita, podemos ler a primeira cobla como "sois digna de mim, que sou rei, porque Deus vos criou perfeita", ou ainda "abdico do meu poder trono real, oferecendo-o a vós, que sois digna dele” (MANSO, 2013, p. 983).
\end{abstract}

Desse modo, percebe-se que Dom Dinis tinha plena consciência da sua posição que era utilizada como uma ferramenta retórico-poética. $\mathrm{O}$ tema de trocar a posição de rei foi trabalhado por outros trovadores, porém a carga de significado e de riso seriam muito maiores com a sua composição, uma vez que ele realmente era rei e um rei que buscava afirmar cada vez mais a sua posição. É possível supor, portanto, que o rei-poeta tinha consciência da sua posição e também do seu papel de formador de uma opinião, levando em consideração o fato de que esses textos eram "compostos para serem falados ou para serem lidos em voz alta e compartilhados com um público ouvinte, investidos de funções rituais, pensados como máquinas para produzir efeitos, [obedecendo] à leis próprias da transmissão oral ou comunitária" (CHARTIER, 2002, p. 13).

Desse modo, a temática da perda do trono por conta de uma aventura amorosa com uma mulher poderia ser utilizada para cativar o público, uma vez que ele estava ciente da situação e da comicidade da situação. Essa ação também pode revelar a intencionalidade de atingir súditos que queria cativar para criar defensores do seu poder, diante do fato de também ter consciência de que a sua política de centralização gerava descontentamentos e opositores.

Esse aspecto pode ser inserido no conceito de negociação com o mundo social de Roger Chartier, o qual se refere a uma relação de troca, de intercâmbio entre o autor e as instituições e práticas sociais. O termo é utilizado para evitar o de reflexo, de reprodução do mundo social na ficção (NAVARRETE, 2011, p. 33).

A partir desse termo é possível compreender que a utilização de técnicas e temas também utilizados pelos demais trovadores estabelece uma relação de diálogo coerente com o que se produzia na época e pela qual o público esperava. Ainda assim, verificamse estratégias retóricas, temáticas e técnicas que emergem da própria tradição e da real condição do rei-trovador. Diante disso, é possível reconhecer que Dom Dinis não tira a coroa para trovar. "Poeta-rei, D. Denis tem na sua poesia alguns elementos (por vezes apenas um lexema ou uma rima) que podem ser interpretados como marcas da sua condição régia" (GONÇALVES, 1993, p. 14). Um exemplo em que essa referência pode ser percebida é a seguinte cantiga:

Praz-mi a mi, senhor, de morrer e praz-m'ende por vosso mal, ca sei que sentiredes qual míngua vos pois hei de fazer; ca nom perde pouco senhor quando perde tal servidor qual perdedes em me perder.

E com mia mort'hei eu prazer porque sei que vos farei tal 
míngua qual fez homem leal, o mais que podia seer, a quem ama, pois morto for; e fostes vós mui sabedor d'eu por vós atal mort'haver. E pero que hei de sofrer a morte mui descomunal, com mia mort'oimais nom m'en chal, por quanto vos quero dizer: ca meu serviç'e meu amor será-vos d'escusar peior que a mim d'escusar viver. E certo podedes saber que, pero s'o meu tempo sal per morte, nom há já i al, que me nom quer'end'eu doer: porque a vós farei maior míngua que fez Nostro Senhor de vassal'a senhor prender.

(LOPES; FERREIRA, 2011)

Nessa composição há a referência à vassalagem quando o trovador se coloca como o servidor leal da dama e, por isso, sua morte será mais sentida por ela que perderá um fiel vassalo. $\mathrm{O}$ código de vassalidade nela exposto pode ter uma utilidade dupla, referindo-se a um mote característico da cantiga de amor ou/e à realidade do laço feudo-vassálico que o rei deixa claro que deve ser cumprido, caso contrário o transgressor sofrerá as consequências, neste caso a senhor perderá o seu melhor vassalo.

Elsa Gonçalves coloca essa característica dionisina de fazer mal à senhor como sendo um senso de justiça, também presente em outras cantigas (Quant' eu, fremosa mha senhor, Tam muito mal mi fazedes, senhor e Assi me trax coitado), em torno das regras do amor-serviço, em que há ressonância com a realidade feudo-vassálica. como rei:

Outra cantiga, agora de amigo, parece também sugerir a identificação do trovador

$$
\begin{aligned}
& \text { Vós que vos em vossos cantares meu } \\
& \text { amigo chamades, creede bem } \\
& \text { que nom dou eu por tal enfinta rem, } \\
& \text { e por aquesto, senhor, vos mand'eu } \\
& \text { que bem quanto quiserdes des aqui } \\
& \text { fazer, façades enfinta de mi. } \\
& \text { Ca demo lev'essa rem que eu der } \\
& \text { por enfinta fazer o mentiral } \\
& \text { de mim, ca me nom monta bem nem mal, } \\
& \text { e por aquesto vos mand'eu, senher, } \\
& \text { que bem quanto quiserdes des aqui } \\
& \text { fazer, façades enfinta de mi. } \\
& \text { Ca mi nom tolh'a mi rem, nem mi dá, } \\
& \text { de s'enfinger de mi mui sem razom } \\
& \text { ao que eu nunca fiz se mal nom, } \\
& \text { e por en, senhor, vos mand'ora já } \\
& \text { que bem quanto quiserdes des aqui } \\
& \text { fazer, façades enfinta de mi. } \\
& \text { [E] estade com'estades de mi, }
\end{aligned}
$$


e enfingede-vos bem des aqui.

(LOPES; FERREIRA, 2011)

A composição apresenta a donzela dirigindo-se ao amigo pelo vocativo senhor, e a utilização do título senher, provençalismo identificado em outras cantigas que, entretanto, é original nessa pelo fato de "que D. Denis é o único trovador que introduz no discurso da cantiga de amigo, pondo-o na boca da personagem feminina, um aristocrático senher que, dirigido ao amigo, poderia querer significar que este, não sendo Deus, era rei..." (GONÇALVES, 1993, p. 18)

É possível perceber que as composições dionisinas seguem um fluxo no qual o trovador percorre diferentes estágios que contribuem para atestar a sua qualidade de amador. De início, ele deveria ser um fenhedor, o aspirante ao amor da dama transformando-se no precador, o do suplicante amoroso que, depois, passa a ser o entender, o namorado que, por fim, se converte no drut, o amante. Assim, essas etapas do fazer-se merecedor do amor da amada podem ser compreendidas em relação com a aquisição dos ideais do amor cortês e da cortesia que deveria ser comprovada para que a dama, sempre superior ao trovador, concedesse o mínimo de reconhecimento a ele. Dessa forma, essa ascensão de aspirante a amante se relaciona a um processo de aperfeiçoamento que ganhou contornos mais nítidos com Marcabru (1129-1150) e seus elementos-chaves cristalizados por Bernard de Ventadour (1145-1195).

Ao recorrer à forma de trovar provençal, Dom Dinis afirma a sua produção dentro de uma tradição.

\begin{abstract}
O trovador tem que pôr em jogo estes mecanismos retóricos para convencer o auditório destinatário das suas composições; um público que assume de bom grado as convenções da ficção poética do canto cortês, que conhece os usos paradigmáticos da poética deste gênero e que está muito capacitado para detetar e valorar as variações de matiz. Porque o poeta quer também, em última instância, persuadir o auditório para que reconheça o seu domínio da arte de trovar; e é por isso que se os procedimentos e os motivos são comuns, o verdadeiro gênio poético mostra-se no emprego que se faz dos mesmos em cada caso concreto (FREIXEDO, 2012, p. 25).
\end{abstract}

Dessa forma, Dom Dinis utiliza a tradição como forma de afirmar sua identidade poética que, contudo, não se dissocia da figura do rei. O rei-trovador revela-se, assim, "um poeta que se move à vontade nas diversas possibilidades que a escola poética galego-portuguesa podia oferecer" (OSÓRIO, 1993, p. 17-18), demonstrando sua consciência e racionalidade retórica-poética, culminando na afirmação de uma produção original que influencia até hoje a cultura e a identidade portuguesa.

\title{
Referências
}


BARBOSA, Pedro Gomes; DIAS, Isabel Barros; FERNANDES, Carla Varela; FRESCO, João; JÚDICE, Nuno; MATOS, Sofia Correia; PALMA, Victor. Actas dos encontros sobre D. Dinis em Odivelas. Lisboa: Edições Colibri/ Câmara Municipal de Odivelas, 2011.

BELTRÁN, Vicenç. O vento lh'as levava: Don Denis y la tradición lírica peninsular. Bulletin Hispanique, tome 86, $\mathrm{n}^{\circ} 1-2,1984$. pp. 5-25. Disponível em: http://www.persee.fr/doc/hispa_0007-4640_1984_num_86_1_4517 . Acesso em: 20/05/2018.

BURKE, Peter. O que é História Cultural? Rio de Janeiro: Jorge Zahar, 2005, p. 32-33.

CHARTIER, Roger. Do palco à página - publicar teatro e ler romances na época moderna, séculos XVI - XVII. Rio de Janeiro: Casa da Palavra, 2002.

CARDEAL, Adriano Tarra Betassa Tovani. Comentários introdutórios à cantiga trovadoresca Querer'eu em maneira de proençal, de Dom Dinis. Troplov, n. 41, outnov., 2013.2 Disponível em: http://www.triplov.com/novaserie.revista/numero 41/index.html . Acesso em: 04/05/2018.

CHARTIER, Roger. Do palco à página - publicar teatro e ler romances na época moderna, séculos XVI-XVII. Rio de Janeiro: Casa da Palavra, 2002.

COELHO, Maria Filomena. Breves reflexões acerca da História medieval no Brasil. In: SILVA, Andréia Cristina Lopes Frazão da, SILVA, Leila Rodrigues. (Org.). SEMANA DE ESTUDOS MEDIEVAIS, 6., 2005, Rio de Janeiro. Atas. Rio de Janeiro: Programa de Estudos Medievais, 2006.

COELHO, António Borges. Portugal medieval (1128-1385). Alfragide: Caminho, 2010.

Comtesse de Dia. Bibliotèque Nationale de France. Disponível em: https://data.bnf.fr/13892674/comtesse_de_die/. Acesso em: 29/12/2019.

DUBY, Georges. A história continua. Rio de Janeiro: Jorge Zahar, 1993.

DUBY, Georges. O cavaleiro, a mulher e o padre. Lisboa: Publicações Dom Quixote, 1988.

FÉRNANDEZ, José Carlos; LOUÇÃO, Paulo Alexandre (coor.). Dinis - O rei civilizador. Uma visão inovadora da vida e obra de um rei justo e sábio. Lisboa: Ésquilo, 2009.

FREIXEDO, Xosé Bieito Arias. Em vós mostrou el seu poder. A poética hiperbólica das cantigas de amor galego-portuguesas. Signum, vol 13, n. 2, 2012.

GIMENEZ, José Carlos. A rainha Isabel nas estratégias políticas da Península Ibérica: 1280-1336. 201 f. Tese (Tese de Doutorado em História). Setor de Ciências Humanas, Letras e Artes, Universidade Federal do Paraná, Curitiba, 2005.

GONÇALVES, Elsa. "D. Denis: um poeta rei e um rei poeta". In: NASCIMENTO, Aires A.; RIBEIRO, Cristina Almeida (org). Literatura Medieval. Volume II. Actas do IV congresso da Associação Hispânica de Literatura Medieval, Lisboa: Edições Cosmos, 1993. 
LANCIANI, Giulia; TAVANI, Giuseppe. Dicionário da literatura medieval galego e portuguesa. Lisboa: Caminho, 1993.

LOPES, Graça Videira. Poesia Provençal - Alguns textos. Medievalista on line, n. 2, 2006.

http://www2.fcsh.unl.pt/iem/medievalista/MEDIEVALISTA2/PDF2/ProvencalPDF.pdf. Acesso em: 25/06/2017.

LOPES, Graça Videira; FERREIRA, Manuel Pedro et al., Cantigas Medievais Galego Portuguesas [base de dados online]. Lisboa: Instituto de Estudos Medievais, FCSH/NOVA. Disponível em: http://cantigas.fcsh.unl.pt.

MACEDO, José Rivair. A mulher na Idade Média. São Paulo: Contexto, 2013.

MANSO, José Henrique. "Estratégias retóricas na poesia trovadoresca de D. Dinis". In: NACUCCHIO, Alex Colman; VITALE, María Alejandra (comp.). II Coloquio Nacional de Retórica "Los códigos persuasivos: Historia y presente". I Congresso internacional de retórica e interdisciplinar, 2013, Mendonza. Libro de Actas. Disponível em: https://ubibliorum.ubi.pt/handle/10400.6/4541 . Acesso em: 04/05/2018.

MATTOSO, José. História de Portugal. Volume II. A monarquia feudal. Lisboa: Estampa, 1997.

MEDEIROS, Márcia Maria de. A história cultural e a história da literatura medieval. Algumas referências à "escritura"do oral e à "oralidade"do escrito.Fronteiras: Revista de História, v. 10, n.17, 2008. Disponível em: http://ojs.ufgd.edu.br/index.php/FRONTEIRAS/article/view/64 . Acesso em: 20/07/2017.

MUNIZ, Márcio Ricardo Coelho. Os estudos de literatura medieval no Brasil. Aedos, vol. 2, $\quad 2009.2, \quad$ Disponível em: http://seer.ufrgs.br/index.php/aedos/article/view/9840/5673 Acessado em: $22 \mathrm{de}$ junho de 2010.

NAVARRETE, Eduardo. Roger Chartier e a Literatura. Revista Tempo, Espaço e Linguagem (TEL), v. $2 \mathrm{n}^{\circ} 3$ p.23-56 Set./Dez, 2011. Disponível em: www.revistas2.uepg.br/index.php/tel/article/download/2660/2422 .

Acesso em: 10/05/2018.

NEMÉSIO, Vitorino. Isabel de Aragão, Rainha Santa. Alfragide: Texto, 2011.

NEVES, Mónica Andrea de Sousa. "Quid sit amor”. O conceito de amor na literatura cortês: a poesia lítica médio-alta alemã e galego-portuguesa - Walther von der Vogelweide e D. Dinis. Dissertação de Mestrado. Porto: Universidade do Porto, 2004.

OLIVEIRA, Ana Rodrigues. Rainhas de Portugal. Lisboa: A esfera dos livros, 2010.

OSÓRIO, Jorge A. D. Dinis: o rei, a língua e o reino. Máthesis. Viseu: Universidade Católica Portuguesa, n. 2, 1993.

PINTO, Américo Cortez. Diónisos. Poeta e Rey. Lisboa: Instituto de Cultura e Língua Portuguesa, 1982.

PIZARRO, José Augusto de Sotto Mayor. D. Dinis. Rio de Mouro: Temas e debates, 2008. 
SANTOS-SILVA, Danielle de Oliveira dos. As favoritas do rei: as relações amorosas entre a nobreza e a realeza portuguesa na Idade Média. Plêthos, n.4, v.1, 2014. Disponível em: www.historia.uff.br/revistaplethos . Acesso em: 22/04/2018.

SENA JUNIOR, Gilberto Ferreira. Realidade versus ficção: a literatura como fonte para escrita da história. In: VI Simpósio Nacional Estado e poder: cultura, 2010, São Cristóvão-SE. Anais VI Simpósio Nacional Estado poder: cultura, 2010. Disponível em: $\quad$ www.historia.uff.br/estadoepoder/6snepc/GT13/GT13GILBERTO.pdf . Acesso em: 08/05/2018.

SERRÃO, Joaquim Veríssimo. História de Portugal. Lisboa: Verbo, 1979.

SEVCENKO, Nicolau. Literatura como missão: tensões sociais e criação cultural na Primeira República. São Paulo: Companhia das Letras, 2003.

SILVA, Joaquim Carvalho. Dicionário da língua portuguesa medieval. Londrina: Eduel, 2009.

ZINK, Michel. "Literatura(s)". In: LE GOFF, Jacques.; SCHMITT, Jean-Claude. Dicionário temático do ocidente medieval. EDUSC: São Paulo, 2002, p. 81.

ZUMTHOR, Paul. Falando de Idade Média. São Paulo: Perspectiva, 2009.

\footnotetext{
${ }^{1}$ Esse artigo constitui-se em um recorte da tese intitulada $O$ trovar coroado de Dom Dinis: modelo de racionalidade artística e identitária do trovadorismo galego-português, defendida em 2018 pelo Programa de Pós-graduação em História da UFPR. A pesquisa contou com financiamento da CAPES.

${ }^{2}$ Remate temático e métrico que finaliza a cantiga.

${ }^{3}$ Presente.

${ }^{4}$ Tradução de Guilherme Gontijo Flores. Disponível em:

http://revistamododeusar.blogspot.com.br/2015/05/guilherme-gontijo-flores-traduz.html . Acesso em: $14 / 05 / 2018$

${ }^{5}$ Ou cobra. Estrofe.
} 